\title{
Putidaredoxin-to-Cytochrome P450cam Electron Transfer: Differences Between the Two Reductive Steps Required for Catalysis $\dagger$
}

\author{
Vadim Yu. Kuznetsov $\ddagger, \perp$, Thomas L. Poulos $\ddagger, \S, \|, \#$, and Irina F. Sevrioukova $\ddagger$, \\ $\$$ Departments of Molecular Biology and Biochemistry, University of California, Irvine, California \\ 92697-3900 \\ $\S$ Departments of Physiology and Biophysics, University of California, Irvine, California 92697-3900 \\ || Departments of Chemistry, University of California, Irvine, California 92697-3900 \\ \# Center in Chemical and Structural Biology, University of California, Irvine, California 92697-3900
}

\begin{abstract}
Cytochrome P450cam (P450cam) is the terminal monooxygenase in a three-component camphor hydroxylating system from Pseudomonas putida. The reaction cycle requires two distinct electron transfer (ET) processes from the [2Fe-2S] containing putidaredoxin (Pdx) to P450cam. Even though the mechanism of interaction and ET between the two proteins has been under investigation for over thirty years, the second reductive step and the effector role of Pdx are not fully understood. We utilized mutagenesis, kinetic, and computer modeling approaches to better understand differences between the two Pdx-to-P450cam ET events. Our results indicate that interacting residues and the ET pathways in the complexes formed between reduced $\mathrm{Pdx}\left(\mathrm{Pdx}^{\mathrm{r}}\right)$ and the ferric and ferrous dioxygen-bound forms of P450cam (oxy-P450cam) are different. Pdx Asp38 and Trp106 were found to be key players in both reductive steps. Compared to the wild type Pdx, the D38A, W106A, and $\Delta 106$ mutants exhibited considerably higher $K_{\mathrm{d}}$ values for ferric P450cam and retained ca. $20 \%$ of the first electron transferring ability. In contrast, the binding affinity of the mutants for oxy-P450cam was not substantially altered while the second ET rates were $<1 \%$. Based on the kinetic and modeling data we conclude that (i) P450cam-Pdx interaction is highly specific in part because it is guided/ controlled by the redox state of both partners; (ii) there are alternative ET routes from $\mathrm{Pdx}^{\mathrm{r}}$ to ferric P450cam and a unique pathway to oxy-P450cam involving Asp38; (iii) Pdx Trp106 is a key structural element that couples the second ET event to product formation possibly via its "push" effect on the heme binding loop.
\end{abstract}

Cytochromes P450 (P450) participate in a variety of metabolic processes and catalyze the monooxygenation of a wide range of aromatic and aliphatic substrates. Mixed function oxidation reactions catalyzed by P450s (Fig. 1) require an input of two electrons that originate from $\mathrm{NAD}(\mathrm{P}) \mathrm{H}$ and are supplied by redox-linked proteins. The most extensively characterized P450, a camphor hydroxylating cytochrome P450cam (P450cam) from Pseudomonas putida, receives reducing equivalents from a $[2 \mathrm{Fe}-2 \mathrm{~S}]$ ferredoxin, putidaredoxin $(\mathrm{Pdx})$, which shuttles between the hemoprotein and a FAD-containing putidaredoxin reductase (Pdr) (1). Proteinprotein interactions in P450cam monooxygenase are highly specific and neither Pdx nor Pdr

\footnotetext{
${ }^{\dagger}$ This research was supported by National Institute of Health Grants GM67637 (to I.F.S.) and GM33688 (to T.L.P.).

*To whom correspondence should be addressed: Tel: 949-824-1953, Fax: 949-824-3280, E-mail: sevrioui@uci.edu.

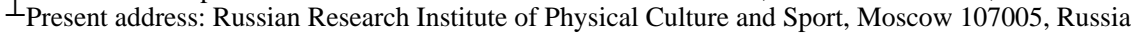


is functionally interchangeable with the homologous proteins from other redox systems (24). The strict requirement of Pdx for reduction of ferrous dioxygen-bound P450cam (oxyP450cam) and product formation is thought to be due to its unique ability to couple electron flow to successful substrate turnover $(3,5,6)$. Owing to technical difficulties in monitoring oxy$\mathrm{P} 450$ cam reduction, this process remains the least studied in the P450cam catalytic cycle.

However, earlier work has shown that the two ET reactions between reduced $\mathrm{Pdx}\left(\mathrm{Pdx}^{\mathrm{r}}\right)$ and ferric and oxy-P450cam may differ in the affinity, binding sites, or reaction mechanism (7$10)$.

The underlying mechanism for the coupling effector role of Pdx is also unclear. Utilization of spectroscopic, kinetic, mutagenesis, NMR, and crystallographic techniques, as well as computer modeling and theoretical calculations (reviewed in ref. $(11,12)$ ) has helped to establish that the Pdx binding/electron transfer (ET) site is located on the proximal surface of P450cam, the nearest approach to the buried heme cofactor and its cysteine ligand, Cys357 (10,13-15). Currently, two mechanisms for the specific effector action of Pdx have been proposed. According to the first, docking of Pdx to the proximal side of P450cam causes a "push" effect on the heme-binding loop and enhances electron donation from the axial thiolate to the heme iron, which in turn facilitates ET to the oxygenated hemoprotein and assists in scission of the $\mathrm{O}-\mathrm{O}$ bond. This mechanism is based on theoretical and experimental data demonstrating the importance of thiolate ligation (reviewed in ref. (16)) and the Fe-S bond perturbation upon P450cam-Pdx complex formation (17-20). In an extended version of the proximal "push" mechanism, the binding of $\mathrm{Pdx}$ results in changes in the distal $\mathrm{O}_{2}$ and substrate binding pockets that lowers the activation energy barrier required for electron transfer and $\mathrm{O}_{2}$ activation $(21,22)$. In the second mechanism, $\mathrm{Pdx}$ acts as an effector by restricting available conformations of P450cam to those that prevent the substrate/intermediate loss. This model is supported by NMR data indicating that $\mathrm{Pdx}^{\mathrm{r}}$ binding causes perturbations in areas remote from the proximal face of $\mathrm{P} 450 \mathrm{cam}$, in particular, in the regions implicated in substrate access and orientation in the distal pocket $(23,24)$.

Based on the x-ray and NMR structures of P450cam and Pdx, respectively, Pochapsky and coworkers (15) generated a model of the P450cam-Pdx complex that has served as a valuable structural guide for investigating redox partner interactions. However, the 1PUT Pdx structure (25) used by Pochapsky' group for model building differs significantly from the high-resolution x-ray structures $(26,27)$ and a refined solution model of the iron-sulfur protein $(28)$. Another limitation on the P450cam-Pdx model is that both protein structures are in the oxidized state. Redox dependent conformational changes in Pdx, detected by NMR and x-ray crystallography methods (28-32), are significant and involve not only residues surrounding the metal cluster but also structural elements located in remote areas, including the Ile32-Asp38 peptide and Arg66. The redox-linked structural differences must be taken into account while modeling $\mathrm{P} 450$ cam-Pdx interactions because the physiologically relevant redox partner of P450cam is $\mathrm{Pdx}$.

In our previous study on the Pdx-Pdr interaction, we investigated the functional role of two residues that undergo major conformational perturbation upon Pdx reduction, Tyr33 and Arg66 (32), as well as Asp38 and Trp106 (Fig. 2) (33). Changes in ET kinetics caused by various mutations were found to be in a good agreement with theoretical predictions suggesting that Tyr33, Arg66, and Trp106 regulate Pdx-Pdr association by controlling how close Pdx can approach Pdr, and that reduction driven movements of Tyr33 and Arg66 could facilitate Pdx dissociation upon ET completion. Insights gained from our work on the Pdx-Pdr system and the availability of crystal structures for reduced and oxidized Pdx as well as oxy-P450cam $(26,34,35)$ prompted us to re-examine the Pdx-P450cam system. In this study we have used mutagenesis, kinetic and computer modeling methods to test the role of specific residues in both the reduction of ferric and oxy-P450cam. Taken together, our experimental and modeling 
results provide an explanation for why the $\mathrm{P} 450 \mathrm{cam}-\mathrm{Pdx}$ interaction is highly specific and how Pdx may execute its effector role.

\section{EXPERIMENTAL PROCEDURES}

\section{Protein Expression and Purification}

Pdx, P450cam, and Pdr were expressed and purified as described previously $(26,33,36,37)$.

\section{Spectroscopic and Stopped Flow Assays}

All conventional UV-visible spectroscopy was performed using a Cary 3 spectrophotometer. Stopped flow experiments were carried out on SX.18MV instrument (Applied Photophysics, UK). Solutions were made anaerobic by multiple evacuation and flushing with pre-purified argon and included an oxygen-scrubbing system consisting of $1 \mathrm{mM}$ glucose and $1 \mathrm{Unit} / \mathrm{ml}$ of glucose oxidase and catalase. Reduction and oxidation of 40-50 $\mu \mathrm{M} \mathrm{Pdx}$ with $5 \mathrm{mM}$ sodium dithionite and $100 \mu \mathrm{M}$ 1,3-dimethoxy-5-methyl-1,4-benzoquinone $\left(\mathrm{CoQ}_{0}\right)$, respectively, was carried out in $100 \mathrm{mM}$ phosphate buffer, $\mathrm{pH} 7.5$, and monitored at $456 \mathrm{~nm}$ at $5-35^{\circ} \mathrm{C}$. Prior to reacting with $\mathrm{CoQ}_{0}$, Pdx was reduced using catalytic amounts of Pdr and sub-equimolar concentrations of NADH. In case of the D38A mutant, that was found to form a complex with $\mathrm{CoQ}_{0}$, the oxidant concentration was $50 \mu \mathrm{M}$. The $\mathrm{CoQ}_{0}$ reductase activity of this mutant was compared to that of WT measured under identical conditions. The kinetic data were analyzed using IgorPro software (WaveMetrics, Inc.). Activation energies $\left(E_{\mathrm{a}}\right)$ and logarithms of preexponential frequency factors $(\ln \mathrm{A})$ for the reactions of Pdx reduction and oxidation were calculated from the plots of $\ln k$ vs $1 / \mathrm{T}$ according to the Arrhenius equation

$$
\ln k=\ln \mathrm{A}-\mathrm{E}_{\mathrm{a}} / \mathrm{RT} \text {. }
$$

Free energies $\left(\Delta \mathrm{G}^{0}\right)$ were determined from the equation

$$
\Delta G^{0}=-n \cdot F \cdot \Delta E_{\mathrm{m}}
$$

where $n$ is a number of electrons transferred during the reaction, $F$ is the Faraday constant, and $\Delta E_{\mathrm{m}}$ is a difference between the redox potentials of an electron donor and acceptor. The $E_{1 / 2}$ values for sodium dithionite, $\mathrm{CoQ}_{0}$, and WT Pdx used in calculations were $-679(38),+100$, and $-240 \mathrm{mV}$ (39), respectively. The redox potentials of Pdx mutants measured by cyclic voltammetry (33) were adjusted by $-78 \mathrm{mV}$ to correct methodical differences. Apparent reorganization energies $(\lambda)$ were calculated from the Marcus equation

$$
E_{\mathrm{a}}=\left(\lambda+\Delta G^{0}\right)^{2} / 4 \lambda
$$

\section{Measurement of the First and the Second Electron Transfer to P450cam}

Transfer of the first electron from reduced Pdx to P450cam was measured in carbon monoxide saturated $50 \mathrm{mM}$ phosphate buffer, $\mathrm{pH} 7.5$, containing $100 \mathrm{mM} \mathrm{KCl}, 1 \mathrm{mM}$ camphor, and an oxygen scrubbing system, using a stopped flow spectrophotometer. Solutions of $2 \mu \mathrm{M}$ $\mathrm{P} 450$ cam were mixed with various concentrations of $\mathrm{Pdx}^{\mathrm{r}}$. Formation of the ferrous-CO form of $\mathrm{P} 450 \mathrm{cam}$ was monitored at $446 \mathrm{~nm}$ at $25^{\circ} \mathrm{C}$. The ET rates to the dioxygen adduct of ferrous $\mathrm{P} 450 \mathrm{cam}$ (oxy-P450cam) were determined at $4^{\circ} \mathrm{C}$ by following degradation of oxy-P450cam into ferric enzyme and hydroxy-camphor at $390 \mathrm{~nm}$ according to the previously described procedure (40) using the sequential double mixing mode of the stopped flow spectrophotometer. Solutions of $5 \mu \mathrm{M}$ P450cam reduced with sub-equimolar amounts of sodium dithionite were first mixed with air-saturated buffer and, after a $1 \mathrm{~s}$ delay, with 4-50 $\mu \mathrm{M} \mathrm{Pdx}$. The second ET process was measured at $391 \mathrm{~nm}$ by following conversion of oxy- 
P450cam into ferric P450cam and hydroxy-camphor. The $k_{\text {cat }}$ and $K_{\mathrm{d}}$ values for the first and second ET reactions were determined from the hyperbolic plots of $k_{\mathrm{obs}} \mathrm{vs}$ [Pdx].

\section{Computer Modeling Studies}

The program GRAMM that uses a surface complementarity algorithm for protein docking (41) was utilized to find possible conformations for the P450cam-Pdx ET complex. The program places each molecule on a grid and performs an exhaustive six-dimensional search through the relative intermolecular translations and rotations using a very efficient Fast Fourier Transform correlation technique and a simple scoring function that measures shape complementarity and penalizes overlaps. Crystal structures of oxidized $\left(\mathrm{Pdx}^{\circ}\right)$ and reduced Pdx (molecules B of 1XLP and 1XLQ, respectively (32)) and those of ferric (molecule A of 1DZ4 (42) and ferrous, dioxygen-bound P450cam (molecule A (35)) without hydrogen atoms were used as input to GRAMM that was run in generic matching and hydrophobic docking modes with $2.1 \AA$ grid step for translations and $10^{\circ}$ increments for rotations. Computergenerated complexes were analyzed to define preferred Pdx docking regions on the surface of $\mathrm{P} 450$ cam and to select models where the heme-[2Fe-2S] distance was within the physiological ET range $(<20 \AA)$. The plausible models were optimized by adjusting side chain positions of interacting amino acid residues using the program "O" (43) and the resulting structures were energy minimized in CNS (44) using CHARMM based forcefield and parameter and topology files provided with the package.

\section{Other calculations}

Possible ET pathways between the redox centers in the model P450cam-Pdx complexes were predicted and analyzed using the program HARLEM (45) with default settings. Either single iron atoms or the entire cofactors were defined as electron donor/acceptor groups. The interface surface area in the P450cam-Pdx complexes was calculated using GRASP (46). Figures were prepared with MOLSCRIPT (47), RASTER3D (48), and PYMOL (49).

\section{RESULTS AND DISCUSSION}

\section{Effect of Mutations on the Electron Accepting and Donating Ability of Pdx}

Key Pdx residues that are either known or predicted to be important in redox partner recognition and ET include Tyr33, Asp38, Arg66, and Trp106 (Fig. 2). Cyclic voltammetry measurements carried out in our previous study revealed significant variations in the kinetic reversibility of the oxidation/reduction process in WT and mutants of Pdx, suggesting that structural reorganization in the protein is coupled to the ET event (33). To better understand the mechanism of redox-dependent perturbations, we estimated activation $\left(E_{\mathrm{a}}\right)$ and reorganization $(\lambda)$ energies for $\mathrm{Pdx}$ reduction and oxidation using sodium dithionite and $\mathrm{CoQ}_{0}$ as a reductant and oxidant, respectively. The $E_{\mathrm{a}}$ and $\lambda$ values were determined from the Arrhenius plots of $\ln k$ vs $1 /$ T (Fig. 3, eq. 1) and from the Marcus equation (eq. 2), respectively.

As seen from Table 1, reorganization energies calculated for Pdx are consistent with those expected in biological ET reactions, $0.2-2.5 \mathrm{eV}$ (50-53). In accord with the crystallographic data (32), the high $\lambda$ value for the reductive step $(2.3 \mathrm{eV})$ suggests that major nuclei, dipole, and charge rearrangements take place upon metal cluster reduction. All mutations led to a slight-to-moderate decrease (3-20\%) of $E_{\mathrm{a}}$, pre-exponential factor (A), and $\lambda$. Changes in the thermodynamic parameters did not correlate with the redox potential fluctuations caused by the mutations but were dependent on how far the altered residues were from the active site (Fig. 2,Table 2). The largest effect was caused by elimination of the Trp106 aromatic ring, most likely due to increased solvent accessibility and polarizability of the $[2 \mathrm{Fe}-2 \mathrm{~S}]$ center. Based on these results we conclude that the 70-80\% decrease in Pdr-to-Pdx ET rates owing to replacement of Tyr33, Asp38, or Arg66 observed previously (33) was due to perturbed protein- 
protein interactions and/or ET pathways and not due to changes in the intrinsic properties of $\operatorname{Pdx}$.

The considerably lower $E_{\mathrm{a}}$ and $\lambda$ values derived for Pdx oxidation (Table 1) indicate that the activation energy barrier for this reaction is lower than that for the reductive step. Another difference between the oxidation and reduction reactions was a more complex effect of the mutations on Pdx oxidation. Compared to WT, $E_{\mathrm{a}}$ and $\lambda$ calculated for Y33F, R66A and R66E Pdx were not significantly different while those determined for the Trp106 and Asp38 mutants decreased by $34-52 \%$. Again, substitutions closest to the active site affected the thermodynamic parameters to a greater extent than those remote from the $[2 \mathrm{Fe}-2 \mathrm{~S}]$ center.

\section{Effect of Mutations on the Electron Transfer to Ferric P450cam (ET1)}

Having established how mutations influence the electron donating ability of Pdx, we next studied the effect of mutations on the two Pdx-to-P450cam ET processes. Since only the first ET from D38N, W106F, and $\Delta 106 \mathrm{Pdx}$ to P450cam has been investigated (54-56), we included these variants in our more comprehensive study. ET1 kinetics was studied by stopped-flow spectrophotometry and monitored at $446 \mathrm{~nm}$, the maximum for the $\mathrm{Fe}^{2+}-\mathrm{CO}$ complex of the hemoprotein (Fig. 4A). The limiting $k_{\mathrm{ET} 1}$ values ( $\left.k_{\mathrm{cat}}\right)$ and apparent dissociation constants $\left(K_{\mathrm{d}}\right)$ calculated from the hyperbolic fits to the plots of $k_{\mathrm{ET} 1} \mathrm{vs}$ [Pdx] are given in Table 2 . Compared to WT Pdx, $K_{\mathrm{d}}$ 's calculated for all of the mutants were 4- to 30-fold lower, indicating a decreased binding affinity for ferric P450cam (Table 2). In contrast, $k_{\text {cat }}$ was affected by the mutations to different extents: Y33A, R66A, and R66E substitutions increased the maximal ET rate by 12-29\%; W106F had no effect; Y33F and D38A substitutions led to a moderate decrease (15-20\%); and D38N, W106A, and $\Delta 106$ mutations lowered $k_{\text {cat }}$ by $80-85 \%$. If any of these residues were comprising a specific ET pathway and hence were critical for the reduction process, one would expect much larger decreases in $k_{\text {cat }}$. Since the major effect of the mutations was on $K_{\mathrm{d}}$, it is reasonable to conclude that the binding rather than the ET event between $\mathrm{Pdx}^{\mathrm{r}}$ and ferric P450cam was predominantly altered, and that the observed decreases in $k_{\text {cat }}$ are due to improper orientation in the Pdx-P450cam complex which slows but does not shutdown ET1. Asp38 and Trp106 were the most important for ET1 since mutations at these sites caused both an increase in $K_{\mathrm{d}}$ and the largest decrease in $k_{\text {cat }}$.

\section{Effect of Mutations on the Electron Transfer to oxy-P450cam (ET2)}

In sharp contrast to ET1, the various mutations introduced in Pdx had only a modest effect on $K_{\mathrm{d}}$ for oxy-P450cam with all except one leading to at most a 2-fold increase (Table 2). The one exception is the D38N substitution, which caused about a 3-4-fold increase in $K_{\mathrm{d}}$ suggesting that, as in ET1, Asp38 is important for binding. The second dramatic difference between the two reductive steps was that the D38A, W106A, and $\Delta 106$ mutations led to $>99 \%$ drop in ET2 $k_{\text {cat }}$. Taken together, the kinetic results indicate that (i) Asp38 and Trp106 are much more important in ET2 than in ET1 and (ii) that the P450cam-Pdx ${ }^{\mathrm{r}}$ complexes formed during the two reductive steps must be structurally different and/or use different ET paths.

Importantly, in contrast to earlier studies (9,57-59), our results and data reported recently by others show that ET2 is considerably faster than ET1 at any Pdx: P450cam ratio $(9,10,40,54$, 60-63). This observation coupled with small differences in kinetic $K_{\mathrm{d}}$ values calculated for the Pdx ${ }^{r}-\mathrm{P} 450$ cam and $\mathrm{Pdx}{ }^{\mathrm{r}}$-oxy-P450cam pairs, 2-15 $(40,63,64)$ vs 4.4-23 $\mu \mathrm{M}(40,60)$, suggests that ET1 rather than ET2 is likely to limit the catalytic turnover in the native camphor hydroxylating system.

Finally, the strikingly different effects of the Tyr33, Asp38, Arg66, and Trp106 substitutions on the ET to and from Pdx indicate that, in contrast to the Pdr-Pdx couple, where Tyr33 and Arg66 play the leading role in controlling the rate-limiting $\operatorname{Pdx}^{\mathrm{r}}$ dissociation (33), Asp38 and 
Trp106 are the key residues that regulate binding and ET between Pdx ${ }^{\mathrm{r}}$ and P450cam. Recruitment of distinct structural elements and the involvement of different regulating mechanisms during the Pdr-Pdx and P450cam-Pdx complex formation seem to be the factors that make protein-protein interactions in P450cam monooxygenase so highly specific.

\section{Modeling Pdx-P450cam Interactions. Optimization of the Pochapsky' Model}

To better understand differences between the two P450cam reduction steps, we utilized a computer modeling approach and searched for plausible P450cam-Pdx orientations that would be in agreement with the experimental data. First, we tested if the complex proposed by Pochapsky and co-workers (15) is a suitable model for either ET1 or ET2. This complex was generated by manually bringing the 1PUT Pdx molecule into the proximal groove of P450cam to achieve the closest possible approach between the cofactors $(12 \AA)$ and to allow interaction between Arg79, Arg109, and Arg112 of P450cam and the C-terminal carboxyl, Asp34, and Asp38 of Pdx, respectively, because an important role of charged residues, in particular Arg 112 $\mathrm{P} 450$, in P450cam-Pdx association had been suggested $(9,13,14,59,65,66)$. To explain the stabilizing effect of Trp106 $\mathrm{Pdx}$ on the inter-protein complex formation and ET mediation $(5,54,55,67)$, the C-terminal residue was placed close to Tyr78 $\mathrm{P} 450$ (ca. $6.0 \AA$ away).

The validity of the Pochapsky' model has been experimentally tested and some but not all predictions have been confirmed $(56,60,68)$. The major disadvantage of the complex, however, was the poorly refined 1PUT Pdx structure used for modeling. To optimize the model, we replaced 1PUT Pdx with the crystallographic molecule B of reduced C73S Pdx (PDB code 1XLQ), pulled it $3.0 \AA$ away to eliminate clashing with P450cam, adjusted side chains of the interface residues and energy minimized the resulting structure that will be referred to as Model 1. Molecule B of 1XLQ Pdx was chosen because it undergoes the largest conformational change upon $[2 \mathrm{Fe}-2 \mathrm{~S}]$ reduction (32). Structural overlay of the original and optimized complexes is shown in Figure 5A. Owing to an increased Fe-Fe distance, protein-protein interactions observed in Model 1 were somewhat different from those in the original complex: Arg $109_{\mathrm{P} 450}-\operatorname{Trp}_{106} \mathrm{Pdx}-\mathrm{COOH}$ and $\mathrm{Arg} 112_{\mathrm{P} 450}-\mathrm{Asp} 38_{\mathrm{Pdx}}$ salt bridges were preserved,

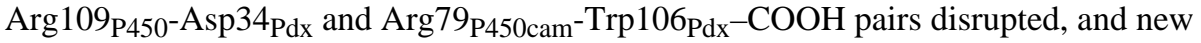
Glu286 $\mathrm{P}_{450}-\mathrm{Arg}_{\mathrm{Pdx}}$ and Lys344 $\mathrm{P}_{50}-\mathrm{Glu}_{\mathrm{P}} 5_{\mathrm{Pdx}}$ charge-charge interactions formed (Table 3). This agrees well with the experimental data showing that $\operatorname{Arg} 109_{\mathrm{P} 450}$ is important for P450cam-Pdx association $(11,68)$ while $A r g 79_{\mathrm{P} 450}$ and Asp34 $\mathrm{Pdx}$ are not $(56,60)$. A salt bridge between Glu65 $5_{\mathrm{Pdx}}$ and Lys344P450, proven to be not essential for the activity of the redox couple $(13,64)$, is situated at the edge of interface and thus may not have a significant impact on a long-range stirring of productive collisions between the proteins. Importantly, the indole ring of Trp106 in Model 1 is sandwiched between the Cys45-Thr47 part of the metal binding loop of Pdx and the aliphatic side chain of Leu356 4450 . These hydrophobic interactions are more extensive than in the original model and better explain the important role of Trp106 in the P450cam binding and ET mediation processes $(5,54,55,67)$.

Depending on whether single iron atoms or the entire cofactor groups were chosen as an electron donor/acceptor, theoretical calculations predicted two different ET pathways (Fig. 5B, Table 4): the Fe-to-Fe route included the iron-sulfur cluster ligand Cys45 and the Leu356Cys357 peptide of $\mathrm{P} 450 \mathrm{cam}$, whereas the [2Fe-2S]-to-heme path proceeded from Cys39 $\mathrm{Pdx}$ through the main and side chain atoms of Asp38 $8_{\mathrm{Pdx}}$ to a heme propionate via $\operatorname{Arg} 112_{\mathrm{P} 450}$. Establishment of the Asp38 $\mathrm{Pdx}_{-}-\mathrm{Arg} 112_{\mathrm{P} 450}$ salt bridge in the P450cam-Pdx ET complex has been widely anticipated $(11,66,68,69)$. Since shortening of the Asp38 side chain to Ala has a moderate effect on ET1 and drastically diminished ET2 (Table 2), we conclude that the optimized Pochapsky' complex can be considered as a plausible model for the first but not the second ET process. Furthermore, since the L356A replacement had no effect on P450cam activity (70), we suggest that the Cys39 ${ }_{\mathrm{Pdx}}-\mathrm{Asp} 38_{\mathrm{Pdx}}-\mathrm{Arg} 112_{\mathrm{P} 450}$ route is predominant during 
ET1 but not unique. Considerably higher values of theoretically predicted ET rates relative to those measured experimentally suggest that the conformation observed in Model 1 may not be easily achieved in solution and a dynamic motion between the proteins (conformational gating) may be required before the actual ET occurs.

\section{Screening for Other Possible P450cam-Pdx Conformations}

In order to find an orientation between P450cam and Pdx that would be in agreement with the ET2 kinetics, we utilized the program GRAMM that performs an exhaustive computational search of all possible configurations to find complexes with the highest surface complementarity (41). The initial stage of inter-protein ET reactions is a translational and rotational diffusion of protein pairs to form associated complexes, a process influenced by electrostatic and static forces communicated through the solvent electrolyte medium. Owing to a small dipole moment and the mostly neutral active site of the Pdx molecule (34), it is likely that surface complementarity rather than electrostatic steering between P450cam and Pdx will guide the first recognition step. In this regard, GRAMM was a suitable program for identifying docking regions in the P450cam-Pdx couple and, as we found, it detected a few "hot" spots on the surface of the hemoprotein where Pdx could preferably bind. Importantly, the docking pattern, shown in detail in the Supporting Information section (Fig. S1-S4), suggested that the P450cam-Pdx association in solution might be guided/controlled not only by the redox state of Pdx $(71,72)$ but also by redox-linked conformational changes in P450cam.

\section{Conformational Dynamics in P450cam}

To understand how the redox state of P450cam could affect Pdx recognition, we compared crystal structures of ferric and oxy-P450cam $(35,42)$ and found that binding of dioxygen to the heme iron causes small but noticeable changes on the proximal face of P450. To accommodate $\mathrm{O}_{2}$ and a catalytically important water molecule in the oxygen-binding groove (Wat234, Fig. 6A), the Asp251-Thr252 peptide in the central I helix undergoes a conformational change. As a result, the groove widens by ca. $0.7 \AA$, Thr 252 moves aside and establishes hydrogen bonds with the ligand and water molecules, and the I helix straightens (Fig. 6B). Through adjacent and neighboring I-H loop and helices $\mathrm{E}$ and $\mathrm{J}$, movement in the I helix transmits to helices $\mathrm{C}$, $\mathrm{D}, \mathrm{H}$, and $\mathrm{K}$ that constrict around the hydrophobic pocket and make it more pronounced (Fig. 6C). These redox-linked changes in surface properties of P450cam, that are likely to be more dramatic in the soluble protein, could facilitate not only recognition and selective binding of one redox form of Pdx over another but also assist in $\mathrm{Pdx}^{\mathrm{O}}$ dissociation when ET is completed.

\section{Modeling the Second Electron Transfer Step}

Four out of fifty top-ranked oxy-P450cam-Pdx ${ }^{\mathrm{r}}$ complexes predicted by GRAMM had a plausible geometry with the Fe-Fe distance less than $20 \AA$ (Fig. 7), the limiting distance for the inter-protein ET to occur at physiologically relevant rates (73). In one of these complexes, Pdx was docked in such a way that its C-terminal Trp106, proven to exhibit conformational freedom in both oxidized and reduced Pdx (67), was positioned above the proximal groove (solution 49, Fig. 7). After optimization, the complex was energy minimized and designated as Model 2 (Fig. 5C), structural and electronic characteristics of which are given in Tables 3 and 4. As seen from Figure 5A and C, switching between $\mathrm{Pdx}^{\mathrm{r}}$ positions in the complexes with ferric and oxy-P450cam (Models 1 and 2, respectively), can be achieved by ca. $50^{\circ}$ rotation around the axis perpendicular to the display. As a result, the side of the Pdx molecule rather than the active site area provides the majority of interactions with P450cam in Model 2. In addition, in this complex (i) the interface becomes two-times larger with more intermolecular contacts; (ii) Trp106 forms extensive hydrophobic and van der Waals contacts with the residues comprising the heme-binding loop; (iii) the side chain of Tyr33 is buried at the interface in a mainly non-polar environment; and (iv) Asp38 establishes ionic and H-bonding interactions 
with Arg364 and His361 of P450cam (Table 3). Involvement of His361 ${ }_{\mathrm{P} 450}$ in redox partner recognition has not yet been tested, whereas the $\mathrm{R} 364 \mathrm{C}$ replacement was shown to result in ca. $30 \%$ decrease in monooxygenase activity (69).

In contrast to Model 1, Arg112 $\mathrm{P} 450$ did not form direct contacts with any Pdx residue and therefore was not predicted to be a part of the ET route. According to the theoretical calculations, the Fe-to-Fe and [2Fe-2S]-to-heme pathways predicted for Model 2 were identical and included the Cys39 ${ }_{\mathrm{Pdx}}-\mathrm{Asp} 38_{\mathrm{Pdx}}$ and His $361_{\mathrm{P} 450}-\mathrm{Gln} 360_{\mathrm{P} 450}$ peptides, the heme ligating Cys357 450 and two hydrogen bonds, Asp38 $8_{\mathrm{Pdx}}(\mathrm{O} \delta)-\mathrm{His} 361_{\mathrm{P} 450}(\mathrm{~N} \delta)$ and Glu360 $\mathrm{P}_{550}(\mathrm{~N})-$

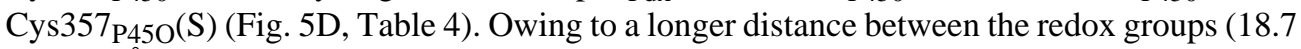
vs. $15.0 \AA$ in Model 1), maximum ET rates predicted for this route were two-to-three orders of magnitude lower and close to those measured experimentally.

Comparison of the theoretical and experimental data shows that Model 2 explains the second ET step rather well. First, in agreement with our kinetic data (Table 2), Model 2 suggests that a residue at position 38 must have a negatively charged side chain to optimally orient Pdx and, most importantly, provide media for a unique ET pathway. Second, according to the model, tryptophan is required at position 106 because only the bulky, rigid indole ring can penetrate into the proximal groove deep enough to push the heme-binding loop, Cys357-His361, and modulate the electronic structure of the heme-thiolate complex, shown to be necessary for acceleration of the O-O bond scission and product formation $(18,19)$. The potential "pushing" ability of Trp106 could explain in part the effector role of Pdx in P450cam catalysis $(3,5,6)$. Third, Model 2 explains why the Tyr33 variants have a lower capability to bind and reduce oxy-P450cam. Extensive hydrophobic interactions established by Trp106 need to be disrupted upon Pdx oxidation and redox-linked movements of the buried Tyr33 side chain (32) could assist dissociation and ensure fast turnover. Fourth, the model complex helps to understand why substitutions of $\operatorname{Arg} 112_{\mathrm{P} 450}$, that do not form direct contacts with Pdx, inhibit ET2 (10, 60). A functionally important Arg 112 provides hydrogen bonds to the heme propionate, defines the conformation of the heme-binding loop, regulates the redox potential and the spin state of the heme iron, and participates in redox partner recognition $(10,14,60,66,69)$. This arginine is situated $4.5 \AA$ away from another basic surface residue, $\operatorname{Arg} 109$, that was demonstrated to be crucial for both P450cam-Pdx ${ }^{\mathrm{r}}$ and oxy-P450cam-Pdx ${ }^{\mathrm{r}}$ association (60). In accord with these experimental data, $\operatorname{Arg} 109$ forms electrostatic interactions with the C-terminal carboxyl and Asp103 of Pdx in Models 1 and 2, respectively (Table 3), and thus is predicted to be important for both ET1 and ET2 complex formations. Based on the theoretical predictions and the proximity of Arg 109 to Arg112, we postulate that the latter residue might assist P450cam-Pdx interaction indirectly by repulsing and directing the Arg 109 side chain into the solvent toward the redox partner.

Since Arg66 is not a part of the protein-protein interface in Model 2 and is ca. $12 \AA$ away from the nearest P450cam residue, the inhibiting effect of Arg66 mutations on the ET2 rates (Table 2) can be due to changes in the overall electrostatic properties of Pdx which could alter the initial recognition step and prevent achieving an optimal orientation for ET2. Although the R66A/E replacements slightly increase reorganization energy for the Pdx oxidation reaction (Table 1), their significant effect on the intrinsic properties of Pdx can be ruled out because neither variant perturbs the ET1 process.

\section{The Effector Role of Pdx}

In addition to the "pushing" ability of Trp106 derived from Model 2, our modeling results reveal another possibility for the coupling effector action of Pdx. Since there is physical evidence that aggregates with the 1:3 and 1:6 P450cam: Pdx ratios can be formed in solution (74) and that complex formation with Pdx induces structural changes in both the proximal side $(17,20)$ and the distal pocket of P450cam $(17,75,76)$, it is possible that the redox controlled 
selective binding between the redox partners detected by GRAMM (Fig. S1-S4) is functionally important. The preferred docking of $\mathrm{Pdx}^{\mathrm{O}}$ near the substrate access channel and along the sides of P450cam could regulate positioning of camphor, help to stabilize the I helix in an energetically strained conformation essential for catalysis, and increase $\mathrm{Pdx}^{\mathrm{r}}$ chances to find the ET site before it looses an electron. This suggestion agrees in part with the NMR data $(23,24)$ showing that $\mathrm{Pdx} \mathrm{x}^{\mathrm{r}}$ causes structural perturbations not only at the proximal side of ferrous CO-bound P450cam but also in the remote areas, in particular, around two sites predicted by GRAMM (Fig. S1-S4). Based on these observations it was concluded that the primary effector role of Pdx is to enforce P450cam conformations that prevent dissociation of substrate/intermediates from the active site prior to turnover and to assist proton/electron coupling. Notably, Rui et al. found that the binding sites for cytochrome $b_{5}$, a non-physiological effector of P450cam monooxygenase $(3,6)$, overlapped with those detected for Pdx ${ }^{\mathrm{r}}$ but were less specific (24). As a control experiment, we analyzed possible docking positions between the ferric and oxy-forms of $\mathrm{P} 450 \mathrm{cam}$ and cytochrome $b_{5}$. In accord with the magnetic resonance and the binding competition studies (77), the docking patterns predicted for Pdx and cytochrome $b_{5}$ had some degree of overlap (Fig. S5 and S6). Unlike the P450cam-Pdx pair, however, none of the top-scored P450cam-cytochrome $b_{5}$ complexes had the effector molecule bound to the proximal groove. This implies that cytochrome $b_{5}$ does not have the correct structure to fit into the active site and explains why cytochrome $b_{5}$ binding has only a minor effect on the P450cam heme environment (20) and its considerably larger excess over Pdx is needed to achieve a similar coupling effect on the camphor hydroxylation reaction (6).

\section{Conclusions}

The results presented in this study show that reduction of ferric (ET1) and oxy-P450cam (ET2) involves formation of different complexes with $\mathrm{Pdx}^{\mathrm{r}}$ and/or different electron transfer paths. Specific mutations introduced in Pdx have different effects on the two reductive steps indicating that Asp38 and Trp106 are much more important in ET2 than in ET1. Computergenerated models of the $\mathrm{P} 450 \mathrm{cam}-\mathrm{Pdx} \mathrm{x}^{\mathrm{r}}$ and oxy-P450cam-Pdx ${ }^{\mathrm{r}}$ complexes are consistent with the experimental results and allow to conclude that one of the reasons that Pdx can act as an effector and couple ET2 to camphor hydroxylation is that its C-terminal Trp106 can approach the heme-binding loop on the proximal surface of P450cam closely enough to modulate the electronic structure of the heme-thiolate complex. Computer modeling also suggests that P450cam-Pdx interaction can be controlled by the redox state of both proteins. This and the potential ability of Pdx to bind in the areas remote from the proximal side and regulate different steps of the monooxygenation reaction explain why Pdx is the most potent effector in the P450cam catalysis.

\section{Supplementary Material}

Refer to Web version on PubMed Central for supplementary material.

\section{Acknowledgements}

Authors thank T. C. Pochapsky for providing coordinates of the model P450cam-Pdx complex.

\section{Abbreviations}

P450cam

cytochrome P450cam from Pseudomonas putida

oxy-P450cam

the ferrous, dioxygen-bound form of P450cam 


\section{$\operatorname{Pdx}^{0}$ and Pdx $x^{r}$}

oxidized and reduced forms of putidaredoxin, respectively

Pdr

putidaredoxin reductase

ET

electron transfer

\section{ET1 and ET2}

the first and the second electron transfer to P450cam

WT

wild type

$\mathrm{CoQ}_{0}$

1,3-dimethoxy-5-methyl-1,4-benzoquinone

\section{References}

1. Katagiri M, Ganguli BN, Gunsalus IC. A soluble cytochrome P450 functional in methylene hydroxylation. J Biol Chem 1968;243:3543-3546. [PubMed: 4297783]

2. Tsai RL, Gunsalus IC, Dus K. Composition and structure of camphor hydroxylase components and homology between putidaredoxin and adrenodoxin. Biochem Biophys Res Commun 1971;45:13001306. [PubMed: 4332595]

3. Tyson CA, Lipscomb JD, Gunsalus IC. The role of putidaredoxin and P450cam in methylene hydroxylation. J Biol Chem 1972;247:5777-5784. [PubMed: 4341491]

4. Geren L, Tuls J, O'Brien P, Millett F, Peterson JA. The involvement of carboxylate groups of putidaredoxin in the reaction with putidaredoxin reductase. J Biol Chem 1986;261:15491-15495. [PubMed: 3096990]

5. Sligar SG, Debrunner PG, Lipscomb JD, Namtvedt MJ, Gunsalus IC. A role of the putidaredoxin COOH-terminus in P450cam (cytochrome m) hydroxylations. Proc Natl Acad Sci USA 1974;71:3906-3910. [PubMed: 4530269]

6. Lipscomb JD, Sligar SG, Namtvedt MJ, Gunsalus IC. Autooxidation and hydroxylation reactions of oxygenated cytochrome P450cam. J Biol Chem 1976;251:1116-1124. [PubMed: 2601]

7. Sligar, SG. PhD thesis. University of Illinois; Urbana: 1975. A kinetic and equilibrium description of camphor hydroxylation by the P450cam monooxygenase system.

8. Hoa GH, Begard E, Debey P, Gunsalus IC. Two univalent electron transfers from putidaredoxin to bacterial cytochrome P450 at subzero temperature. Biochemistry 1978;17:2835-2839. [PubMed: 687565]

9. Brewer CB, Peterson JA. Single turnover kinetics of the reaction between oxycytochrome P450cam and reduced putidaredoxin. J Biol Chem 1988;263:791-798. [PubMed: 2826462]

10. Unno M, Shimada H, Toba Y, Makino R, Ishimura Y. Role of Arg112 of cytochrome P450cam in the electron transfer from reduced putidaredoxin. Analyses with site-directed mutants. J Biol Chem 1996;271:17869-17874. [PubMed: 8663375]

11. Shimada H, Nagano S, Hori H, Ishimura Y. Putidaredoxin-cytochrome P450cam interaction. J Inorg Biochem 2001;83:255-260. [PubMed: 11293545]

12. Mueller, EJ.; Loida, PJ.; Sligar, SG. Twenty-five years of P450cam Research. In: Montellano, PROd, editor. Cytochrome P450: Structure, Mechanism, and Biochemistry. 2. Plenum Press; New York: 1995. p. 83-125.

13. Stayton PS, Sligar SG. The cytochrome P450cam binding surface as defined by site-directed mutagenesis and electrostatic modeling. Biochemistry 1990;29:7381-7386. [PubMed: 2223769]

14. Koga H, Sagara Y, Yaoi T, Tsujimura M, Nakamura K, Sekimizu K, Makino R, Shimada H, Ishimura Y, Yura K. Essential role of the Arg112 residue of cytochrome P450cam for electron transfer from reduced putidaredoxin. FEBS Letters 1993;331:109-113. [PubMed: 8405387] 
15. Pochapsky TC, Lyons TA, Kazanis S, Arakaki T, Ratnaswamy G. A structure-based model for cytochrome P450cam-putidaredoxin interactions. Biochimie 1996;78:723-33. [PubMed: 9010601]

16. Shaik S, Kumar D, de Visser SP, Altun A, Thiel W. Theoretical perspective on the structure and mechanism of cytochrome P450 enzymes. Chem Rev 2005;105:2279-2328. [PubMed: 15941215]

17. Unno M, Christian JF, Benson DE, Gerber NC, Sligar SG, Champion PM. Resonance Raman investigations of cytochrome P450cam complexed with putidaredoxin. J Am Chem Soc 1997;119:6614-6620.

18. Yoshioka S, Takahashi S, Ishimori K, Morishima I. Roles of the axial push effect in cytochrome P450cam studied with the site-directed mutagenesis at the heme proximal site. J Inorg Biochem 2000;81:141-151. [PubMed: 11051559]

19. Yoshioka S, Tosha T, Takahashi S, Ishimori K, Hori H, Morishima I. Roles of the proximal hydrogen bonding network in cytochrome P450cam-catalyzed oxygenation. J Am Chem Soc 2002;124:1457114579. [PubMed: 12465966]

20. Unno M, Christian JF, Sjodin T, Benson DE, Macdonald ID, Sligar SG, Champion PM. Complex formation of cytochrome P450cam with Putidaredoxin. Evidence for protein-specific interactions involving the proximal thiolate ligand. J Biol Chem 2002;277:2547-2553. [PubMed: 11706033]

21. Tosha T, Yoshioka S, Ishimori K, Morishima I. L358P mutation on cytochrome P450cam simulates structural changes upon putidaredoxin binding: the structural changes trigger electron transfer to oxyP450cam from electron donors. J Biol Chem 2004;279:42836-42843. [PubMed: 15269211]

22. Nagano S, Tosha T, Ishimori K, Morishima I, Poulos TL. Crystal structure of the cytochrome P450cam mutant that exhibits the same spectral perturbations induced by putidaredoxin binding. J Biol Chem 2004;279:42844-42849. [PubMed: 15269210]

23. Pochapsky SS, Pochapsky TC, Wei JW. A model for effector activity in a highly specific biological electron transfer complex: The cytochrome P450cam-putidaredoxin couple. Biochemistry 2003;42:5649-5656. [PubMed: 12741821]

24. Rui L, Pochapsky SS, Pochapsky TC. Comparison of the complexes formed by cytochrome P450cam with cytochrome $b_{5}$ and putidaredoxin, two effectors of camphor hydroxylase activity. Biochemistry 2006;45:3887-3897. [PubMed: 16548516]

25. Pochapsky TC, Ye XM, Ratnaswamy G, Lyons TA. An NMR-derived model for the solution structure of oxidized putidaredoxin, a 2Fe-2S ferredoxin from Pseudomonas. Biochemistry 1994;33:64246432. [PubMed: 8204575]

26. Sevrioukova IF, Garcia C, Li H, Bhaskar B, Poulos TL. Crystal structure of putidaredoxin, the [2Fe-2S] component of the P450cam monooxygenase system from Pseudomonas putida. J Mol Biol 2003;333:377-392. [PubMed: 14529624]

27. Smith N, Mayhew M, Holden MJ, Kelly H, Robinson H, Heroux A, Vilker VL, Gallagher DT. Structure of C73G putidaredoxin from Pseudomonas putida. Acta Cryst Biol Crystallogr 2004;D 60:816-822.

28. Jain NU, Tjioe E, Savidor A, Boulie J. Redox-dependent structural differences in putidaredoxin derived from homologous structure refinement via residual dipolar couplings. Biochemistry 2005;44:9067-9078. [PubMed: 15966730]

29. Jain NU, Pochapsky TC. Redox dependence of hyperfine-shifted ${ }^{13} \mathrm{C}$ and ${ }^{15} \mathrm{~N}$ resonances in putidaredoxin. J Am Chem Soc 1998;120:12984-12985.

30. Sari N, Holden MJ, Mayhew MP, Vilker VL, Coxon B. Comparison of backbone dynamics of oxidized and reduced putidaredoxin by ${ }^{15}$ N NMR relaxation measurements. Biochemistry 1999;38:98629871. [PubMed: 10433692]

31. Pochapsky TC, Kostic M, Jain N, Pejchal R. Redox-dependent conformational selection in a $\mathrm{Cys}_{4} \mathrm{Fe}_{2} \mathrm{~S}_{2}$ ferredoxin. Biochemistry 2001;40:5602-5614. [PubMed: 11341825]

32. Sevrioukova IF. Redox-dependent structural reorganization in putidaredoxin, a vertebrate-type [2Fe-2S] ferredoxin from Pseudomonas putida. J Mol Biol 2005;347:607-621. [PubMed: 15755454]

33. Kuznetsov VY, Blair E, Farmer PJ, Poulos TL, Pifferitti A, Sevrioukova IF. The putidaredoxin reductase-putidaredoxin electron transfer complex: theoretical and experimental studies. J Biol Chem 2005;280:16135-16142. [PubMed: 15716266] 
34. Sevrioukova IF, Li H, Poulos TL. Crystal structure of putidaredoxin reductase from Pseudomonas putida, the final structural component of the cytochrome P450cam monooxygenase. J Mol Biol 2004;336:889-902. [PubMed: 15095867]

35. Nagano S, Poulos TL. Crystallographic study on the dioxygen complex of wild-type and mutant cytochrome P450cam. Implications for the dioxygen activation mechanism. J Biol Chem 2005;280:31659-31663. [PubMed: 15994329]

36. Gunsalus IC, Wagner GC. Bacterial P450cam methylene monooxygenase components: cytochrome m, putidaredoxin, and putidaredoxin reductase. Methods Enzymol 1978;52:166-188. [PubMed: 672627]

37. Sevrioukova IF, Poulos TL. Putidaredoxin reductase: A new function for an old protein. J Biol Chem 2002;277:25831-25839. [PubMed: 12011076]

38. Mayhew SG. The redox potential of dithionite and $\mathrm{SO}^{-2}$ from equilibrium reactions with flavodoxins, methyl viologen and hydrogen plus hydrogenase. Eur J Biochem 1978;85:535-547. [PubMed: 648533]

39. Reipa V, Holden MJ, Mayhew MP, Vilker VL. Temperature dependence of the formal reduction potential of putidaredoxin. Biochim Biophys Acta 2000;1459:1-9. [PubMed: 10924895]

40. Tosha T, Yoshioka S, Hori H, Takahashi S, Ishimori K, Morishima I. Molecular mechanism of the electron transfer reaction in cytochrome P450cam-putidaredoxin: roles of glutamine 360 at the heme proximal site. Biochemistry 2002;41:13883-13893. [PubMed: 12437345]

41. Vakser IA, Aflalo C. Hydrophobic docking - a proposed enhancement to molecular recognition techniques. Proteins 1994;20:320-329. [PubMed: 7731951]

42. Schlichting I, Berendzen J, Chu K, Stock AM, Maves SA, Benson DE, Sweet RM, Ringe D, Petsko GA, Sligar SG. The catalytic pathway of cytochrome P450cam at atomic resolution. Science 2000;287:1615-1622. [PubMed: 10698731]

43. Jones TA, Zou JY, Cowan SW, Kjeldgaard M. Improved methods for building protein models in electron density maps and the location of errors in these models. Acta Crystallogr A 1991;47:110 119. [PubMed: 2025413]

44. Brunger AT, Adams PD, Clore GM, DeLano WL, Gros P, GrosseKunstleve RW, Jiang JS, Kuszewski J, Nilges M, Pannu NS, Read RJ, Rice LM, Simonson T, Warren GL. Crystallography + NMR system: A new software suite for macromolecular structure determination. Acta Crystallogr D 1998;54:905921. [PubMed: 9757107]

45. Kurnikov, IV. HARLEM molecular modeling package v 10. Department of Chemistry, University of Pittsburgh; Pittsburgh, PA: 2000.

46. Nicholls A, Sharp KA, Honig B. Protein folding and association: insights from the interfacial and thermodynamic properties of hydrocarbons. Proteins 1991;11:281-296. [PubMed: 1758883]

47. Kraulis JP. MOLSCRIPT: a program to produce both detailed and schematic plots of protein structures. J Appl Crystallogr 1991;24:946-950.

48. Merritt EA, Bacon DJ. RASTER3D: photorealistic molecular graphics. Methods Enzymol 1997;277:505-524. [PubMed: 18488322]

49. DeLano, WL. The PyMOL molecular graphics system. Delano Scientific; San Carlos, CA, USA: 2002.

50. Warshel A, Chu ZT, Parson WW. Dispersed polaron simulations of electron transfer in photosynthetic reaction centers. Science 1989;246:112-116. [PubMed: 2675313]

51. Brooks HB, Davidson VL. Kinetic and thermodynamic analysis of a physiologic intermolecular electron-transfer reaction between methylamine dehydrogenase and amicyanin. Biochemistry 1994;33:5696-5701. [PubMed: 8180195]

52. Ivkovic-Jensen MM, Kostic NM. Effects of viscosity and temperature on the kinetics of the electrontransfer reaction between the triplet state of zinc cytochrome $\mathrm{c}$ and cupriplastocyanin. Biochemistry 1997;36:8135-8144. [PubMed: 9201962]

53. Lanzilotta WN, Parker VD, Seefeldt LC. Electron transfer in nitrogenase analyzed by Marcus theory: evidence for gating by MgATP. Biochemistry 1998;37:399-407. [PubMed: 9425061]

54. Davies MD, Qin L, Beck JL, Suslick KS, Koga H, Horiuchi T, Sligar SG. Putidaredoxin eduction of cytochrome P450cam - Dependence of electron transfer on the identity of putidaredoxins C-terminal amino acid. J Am Chem Soc 1990;112:7396-7398. 
55. Davies MD, Sligar SG. Genetic variants in the putidaredoxin-cytochrome P450cam electron-transfer complex: identification of the residue responsible for redox-state-dependent conformers. Biochemistry 1992;31:11383-11389. [PubMed: 1445875]

56. Holden M, Mayhew M, Bunk D, Roitberg A, Vilker V. Probing the interactions of putidaredoxin with redox partners in camphor P450 5-monooxygenase by mutagenesis of surface residues. J Biol Chem 1997;272:21720-21725. [PubMed: 9268300]

57. Pederson, TT.; Austin, RH.; Gunsalus, IC. Microsomes and Drug Oxidations. Ulrich, V., editor. Pergamon Press; Elmsford, NY: 1977. p. 275-283.

58. Peterson, JA.; Mock, DM. Cytochromes P450 and b5. Cooper, DY.; Snyder, ORR.; Witmer, C., editors. Plemun Press; New York: 1975. p. 311-324.

59. Brewer CB, Peterson JA. Single turnover studies with oxy-cytochrome P-450cam. Arch Biochem Biophys 1986;249:515-521. [PubMed: 3753015]

60. Nagano S, Shimada H, Tarumi A, Hishiki T, Kimata-Ariga Y, Egawa T, Suematsu M, Park SY, Adachi S, Shiro Y, Ishimura Y. Infrared spectroscopic and mutational studies on putidaredoxininduced conformational changes in ferrous CO-P450cam. Biochemistry 2003;42:14507-14514. [PubMed: 14661963]

61. Peterson JA, Mock DM. Cytochrome P450cam and putidaredoxin interaction during electron transfer. Acta Biol Med Germ 1979;38:153-162. [PubMed: 229672]

62. Furukawa Y, Morishima I. The role of water molecules in the association of cytochrome P450cam with putidaredoxin. J Biol Chem 2001;276:12983-12990. [PubMed: 11278642]

63. Sevrioukova IF, Hazzard JT, Tollin G, Poulos TL. Laser flash induced electron transfer in P450cam monooxygenase: Putidaredoxin reductase - putidaredoxin interaction. Biochemistry 2001;40:1059210600. [PubMed: 11524002]

64. Aoki M, Ishimori K, Morishima I. Roles of negatively charged surface residues of putidaredoxin in interactions with redox partners in P450cam monooxygenase system. Biochim Biophys Acta 1998;1386:157-167. [PubMed: 9675266]

65. Hintz MJ, Peterson JA. The kinetics of reduction of cytochrome P450cam by reduced putidaredoxin. J Biol Chem 1981;256:6721-6728. [PubMed: 7240239]

66. Nakamura K, Horiuchi T, Yasukochi T, Sekimizu K, Hara T, Sagara Y. Significant contribution of arginine 112 and its positive charge of Pseudomonas putida cytochrome P450cam in the electron transport from putidaredoxin. Biochim Biophys Acta 1994;1207:40-48. [PubMed: 8043608]

67. Stayton PS, Sligar SG. Structural microheterogeneity of a tryptophan residue required for efficient biological electron transfer between putidaredoxin and cytochrome P450cam. Biochemistry 1991;30:1845-1851. [PubMed: 1993199]

68. Shimada H, Nagano S, Ariga Y, Unno M, Egawa T, Hishiki T, Ishimura Y, Masuya F, Obata T, Hori H. Putidaredoxin-cytochrome P450cam interaction. Spin state of the heme iron modulates putidaredoxin structure. J Biol Chem 1999;274:9363-9369. [PubMed: 10092615]

69. Lo KK, Wong LL, Hill HA. Surface-modified mutants of cytochrome P450cam: enzymatic properties and electrochemistry. FEBS Letters 1999;451:342-346. [PubMed: 10371217]

70. Roitberg AE, Holden MJ, Mayhew MP, Kurnikov IV, Beratan DN, Vilker VL. Binding and electron transfer between putidaredoxin and cytochrome P450cam - Theory and experiments. J Am Chem Soc 1998;120:8927-8932.

71. Sligar SG, Gunsalus IC. A thermodynamic model of regulation: modulation of redox equilibria in camphor monoxygenase. Proc Natl Acad Sci U S A 1976;73:1078-1082. [PubMed: 1063390]

72. Hintz MJ, Mock DM, Peterson LL, Tuttle K, Peterson JA. Equilibrium and kinetic studies of the interaction of cytochrome P-450cam and putidaredoxin. J Biol Chem 1982;257:14324-14332. [PubMed: 7142212]

73. Page CC, Moser CC, Chen X, Dutton PL. Natural engineering principles of electron tunnelling in biological oxidation-reduction. Nature 1999;402:47-52. [PubMed: 10573417]

74. Dus, K.; Lipscomb, JD.; Gunsalus, IC. Abstracts of the 162nd American Chemical Society Meeting. Washington, D.C.; September 12-17, 1971. 1971.

75. Shiro Y, Iizuka T, Makino R, Ishimura Y, Morishima I. ${ }^{15} \mathrm{~N}$ NMR study on cyanide $\left(\mathrm{C}^{15} \mathrm{~N}-\right)$ complex of cytochrome P450cam. Effects of d-camphor and putidaredoxin on the iron-ligand structure. J Am Chem Soc 1989;111:7707-7711. 
76. Sjodin T, Christian JF, Macdonald ID, Davydov R, Unno M, Sligar SG, Hoffman BM, Champion PM. Resonance Raman and EPR investigations of the D251N oxycytochrome P450cam/ putidaredoxin complex. Biochemistry 2001;40:6852-6859. [PubMed: 11389599]

77. Stayton PS, Poulos TL, Sligar SG. Putidaredoxin competitively inhibits cytochrome $b_{5}$-cytochrome P450cam association: a proposed molecular model for a cytochrome P-450cam electron-transfer complex. Biochemistry 1989;28:8201-8205. [PubMed: 2690937]

78. CCP4. Collaborative Computational Project Number 4. The CCP4 suite programs for protein crystallography. Acta Crystallogr D 1994;50:760-763. [PubMed: 15299374]

79. Poulos TL, Finzel BC, Gunsalus IC, Wagner GC, Kraut J. J Biol Chem 1985;260:16122-30. [PubMed: 4066706] 


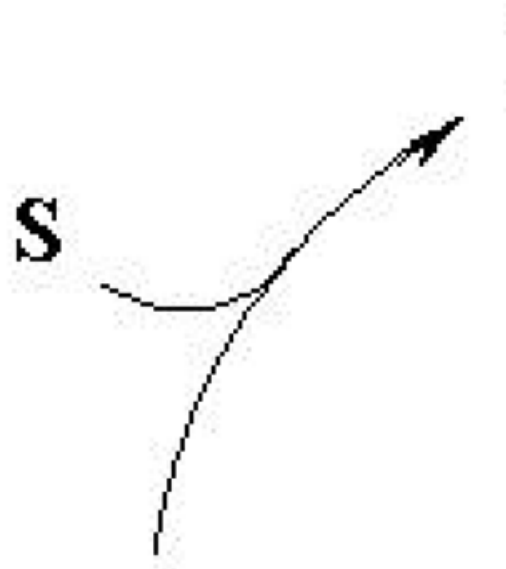

$\mathrm{P}_{450}{ }^{3+}$
$\left[\mathrm{P450}{ }^{3+}-\mathrm{S}\right]$

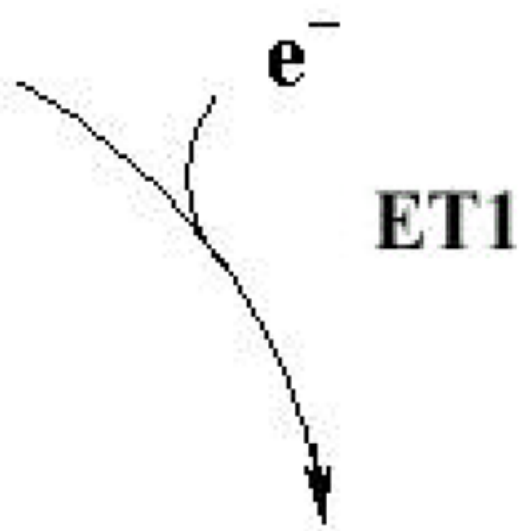

$\left[\mathrm{P}^{450}{ }^{2+}-\mathrm{S}\right]$
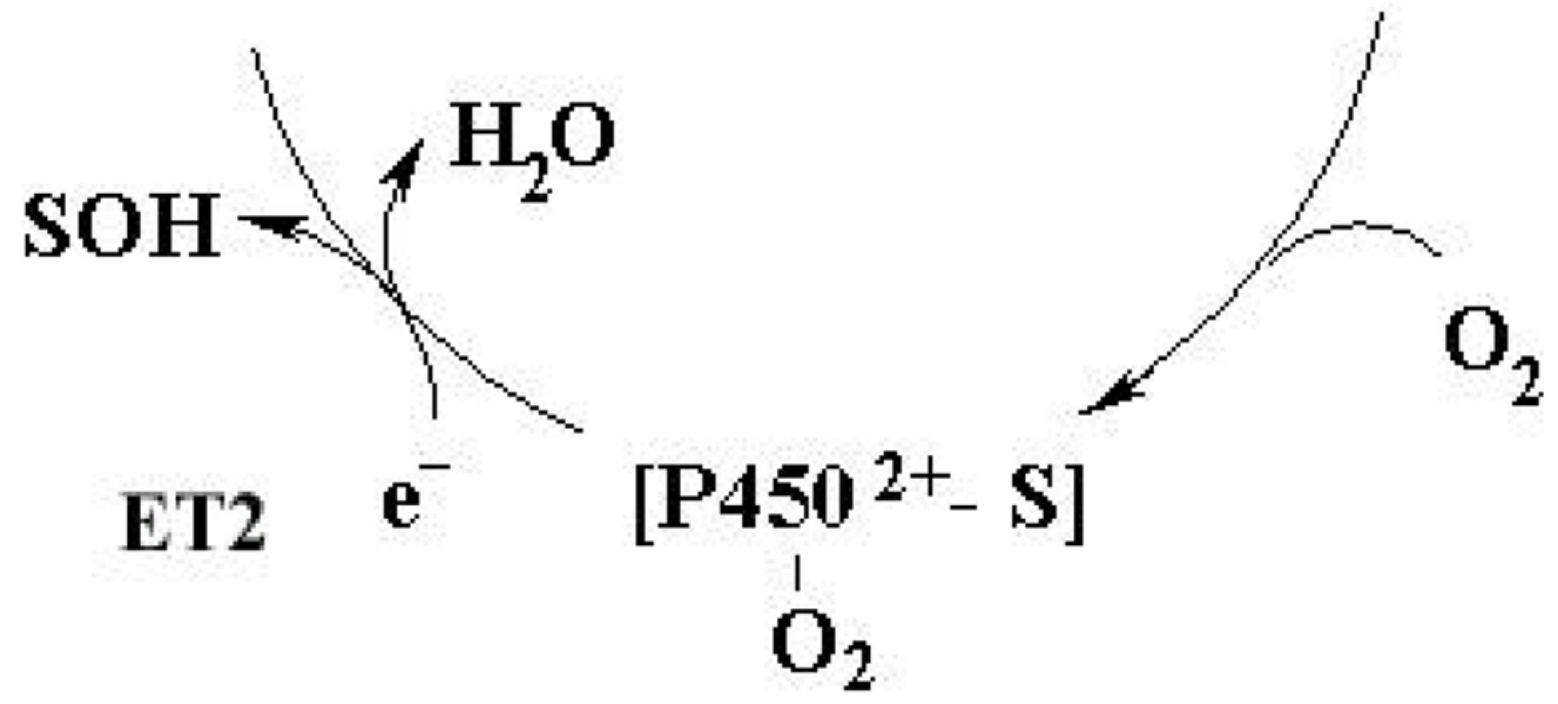

Figure 1.

Fundamental cycle of cytochrome $\mathrm{P} 450 . \mathrm{P} 450^{3+}$ - resting state; $\mathrm{S}-$ substrate; $\left[\mathrm{P} 450^{3+}{ }_{-} \mathrm{S}\right]-$ substrate-bound ferric form; $\left[\mathrm{P} 450^{2+}{ }_{-} \mathrm{S}\right]$ - substrate-bound ferrous form; $\left[\mathrm{O}_{2}-\mathrm{P} 450^{2+}{ }_{-} \mathrm{S}\right]-$ dioxygen- and substrate-bound ferrous form; $\mathrm{SOH}$ - hydroxylated substrate. In P450cam monooxygenase, the first electron (ET1) can be transferred to P450cam from any reducing agent with a suitable redox potential but only Pdx can deliver the second electron (ET2). 


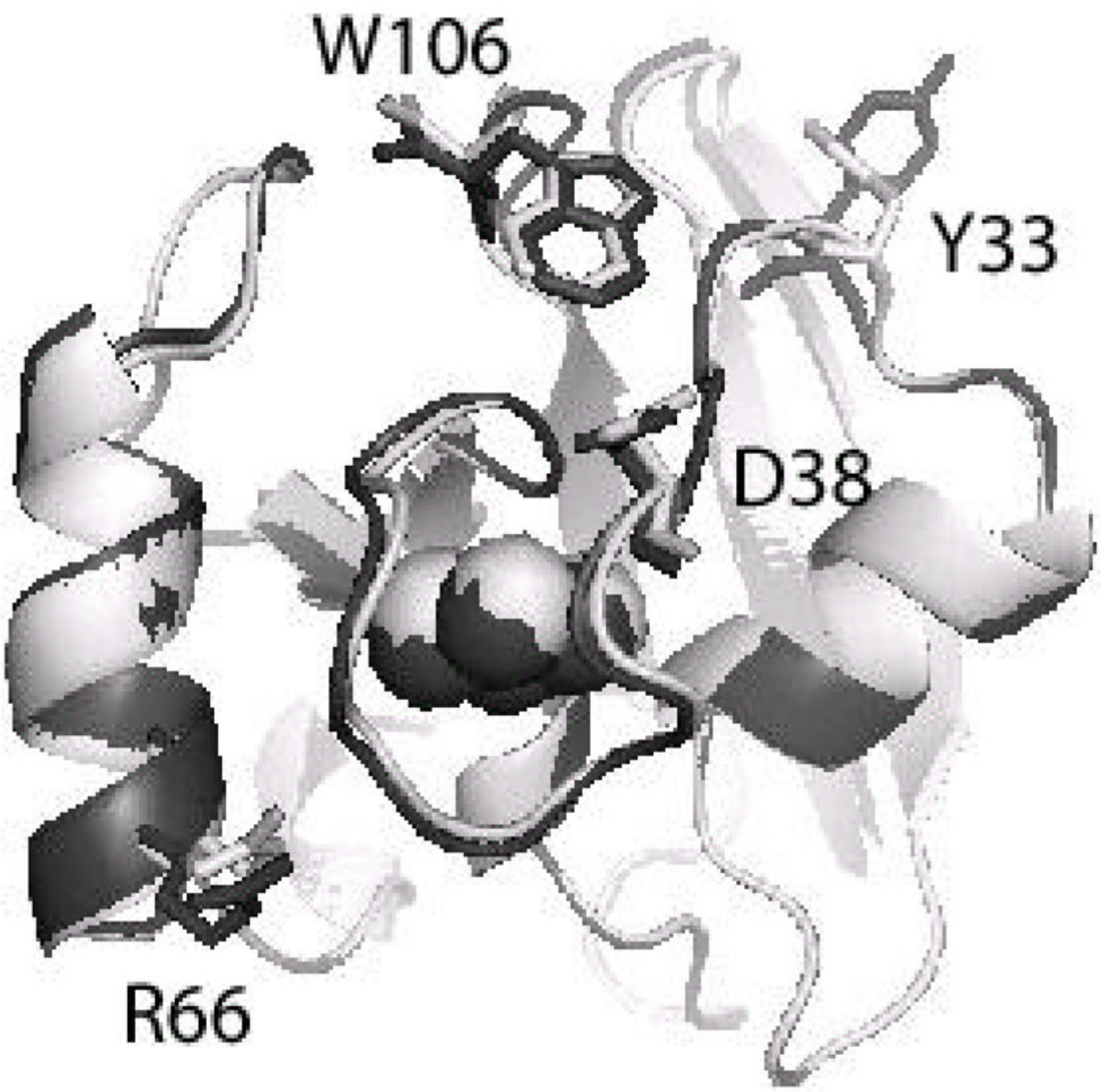

Figure 2.

A view at the active site of Pdx. The least-squares superposition of the crystal structures of oxidized (white) and reduced (black) C73S Pdx molecules (molecules B, PDB codes 1XLP and $1 \mathrm{XLQ}$, respectively (32)) was performed using the program LSQMAN (78). The [2Fe-2S] metal center and the mutated residues are shown in cpk and ball-and-stick representation, respectively. 

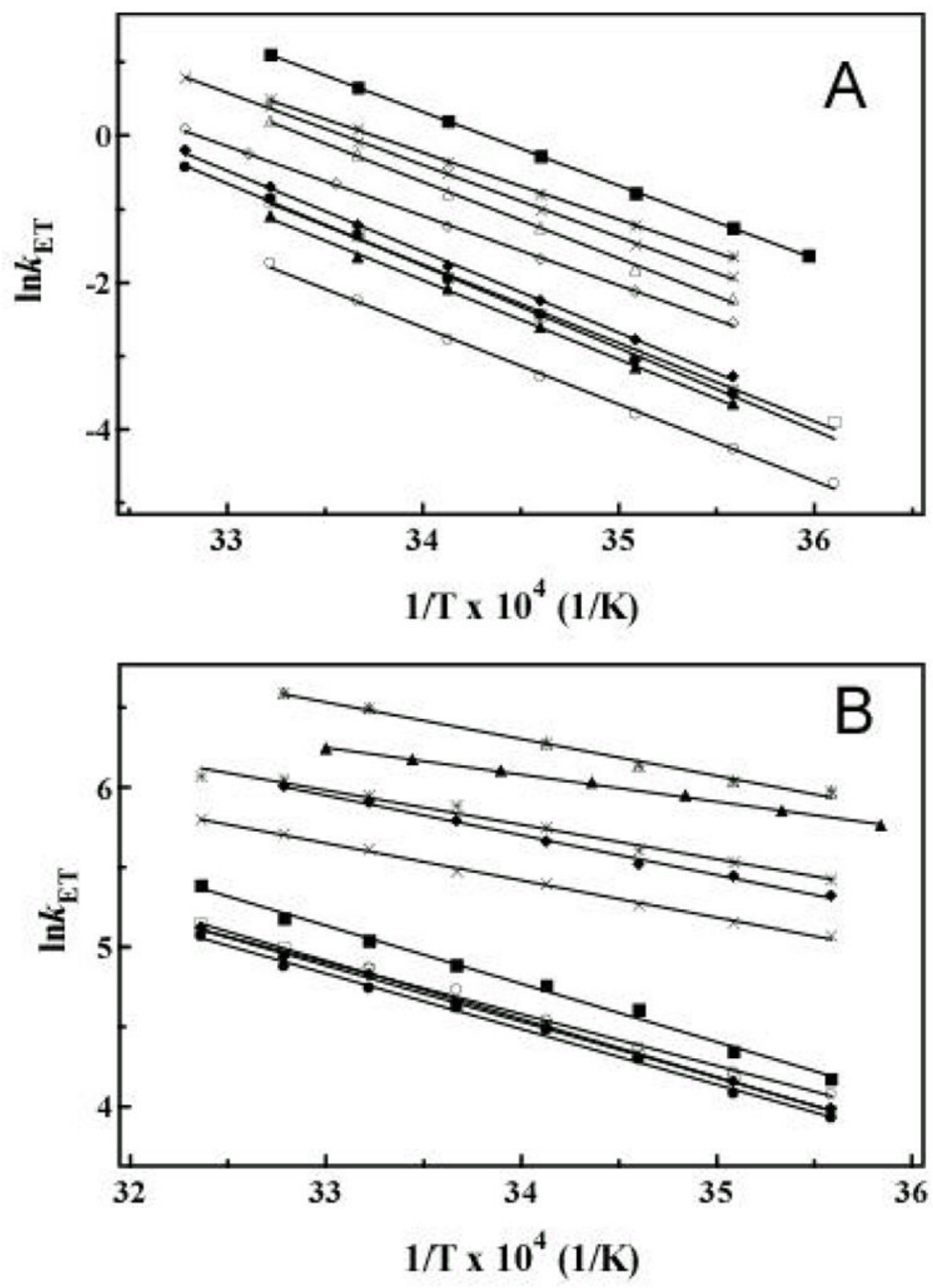

Figure 3.

Thermodynamic analysis of the ET reactions to $(A)$ and from of Pdx $(B)$. Reduction and oxidation of WT (filled circle), Y33A (open circle), Y33F (filled square), D38A (filled triangle), D38N (open triangle), R66E (open square), R66A (filled diamond), $\Delta 106$ (open diamond), W106A (x), and W106F (*) with $5 \mathrm{mM}$ sodium dithionite and $100 \mu \mathrm{M} \mathrm{CoQ}$, respectively, was monitored under anaerobic conditions at $456 \mathrm{~nm}$ and $4{ }^{\circ} \mathrm{C}$. The reaction buffer contained $50 \mathrm{mM}$ phosphate, $\mathrm{pH} 7.5$, and oxygen scrubbing system consisting of $1 \mathrm{mM}$ glucose, $1 \mathrm{Unit} / \mathrm{ml}$ catalase, $1 \mathrm{Unit} / \mathrm{ml}$ glucose oxidase, and 40-50 $\mu \mathrm{M}$ Pdx. Prior to reaction with $\mathrm{CoQ}_{0}$, Pdx was reduced using catalytic amounts of Pdr and sub-equimolar concentrations of $\mathrm{NADH}$. The natural logarithms of the observed rate constants $\left(k_{\mathrm{ET}}\right)$ for the reduction and 
oxidation reactions were plotted against $1 / \mathrm{T}$. Each point represents an average of at least three measurements. Solid lines are linear fits to the Arrhenius equation (eq. 1). The derived thermodynamic parameters are given in Table 1. 

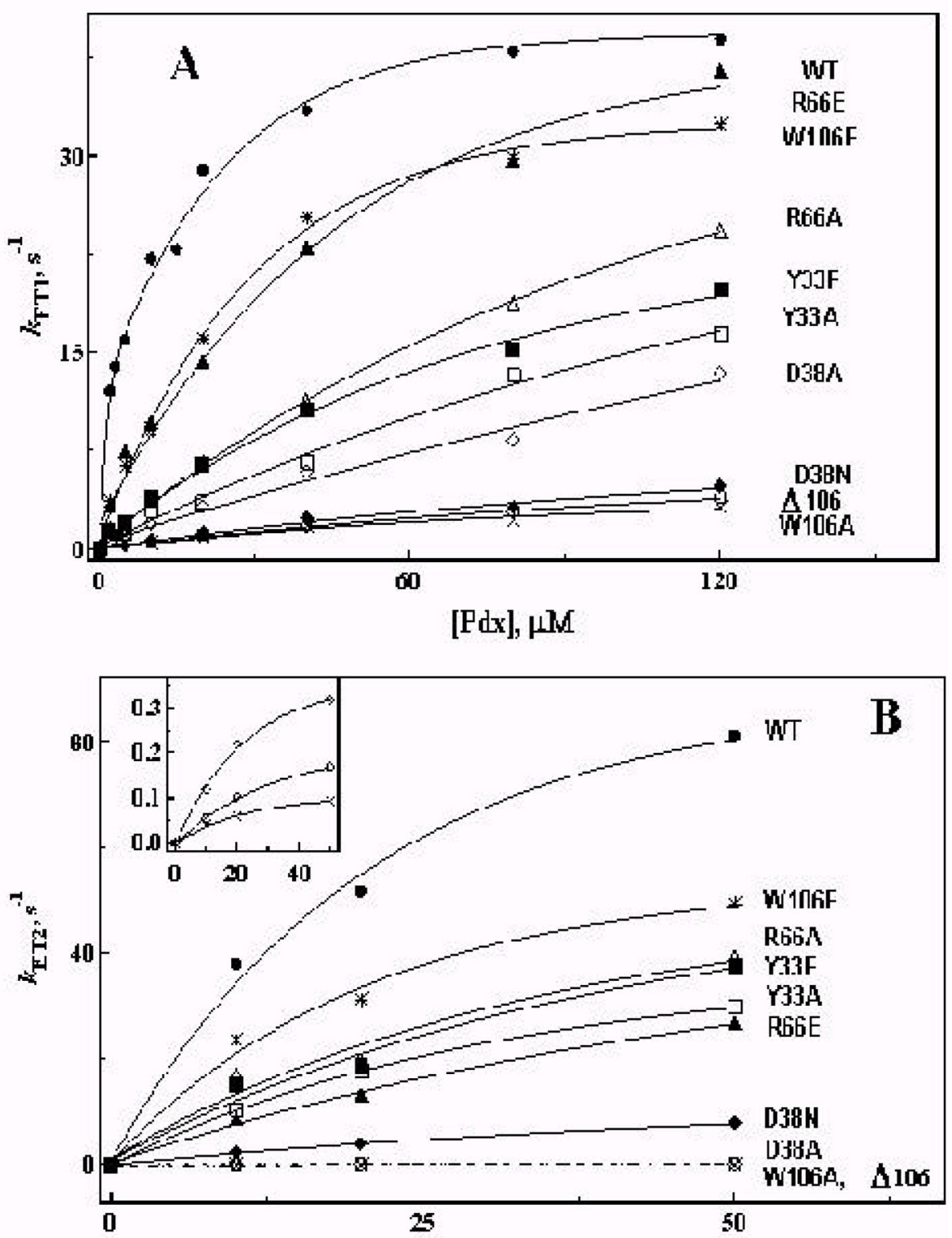

$[\mathrm{Pdx}], \mu \mathrm{NM}$

Figure 4.

Plots of the observed ET rate constants vs $[\mathrm{Pdx}]$ for the transfer of an electron from $\mathrm{Pdx}^{\mathrm{r}}$ to ferric $(A)$ and oxy-P450cam $(B)$. Reduction of $2 \mu \mathrm{M}$ ferric $\mathrm{P} 450$ cam with various concentrations of $\mathrm{Pdx}^{\mathrm{r}}$ was monitored at $446 \mathrm{~nm}$ and $25^{\circ} \mathrm{C}$ to follow formation of the ferrous$\mathrm{CO}$ form in carbon monoxide saturated $50 \mathrm{mM}$ phosphate buffer, $\mathrm{pH} 7.5$, containing $100 \mathrm{mM}$ $\mathrm{KCl}, 1 \mathrm{mM}$ camphor, and an oxygen scrubbing system. ET from $\mathrm{Pdx}^{\mathrm{r}}$ to oxy-P450cam was measured at $390 \mathrm{~nm}$ and $4{ }^{\circ} \mathrm{C}$ using sequential double mixing mode of the stopped flow spectrophotometer to follow decomposition of oxy-P450cam into ferric enzyme and hydroxycamphor. The $k_{\text {cat }}$ and $K_{\mathrm{d}}$ values for the reactions were determined from the hyperbolic fits shown in solid lines. Inset $B$ is a zoomed in view at the $k_{\mathrm{ET} 2} \mathrm{vs}$ [Pdx] plots for the D38A (open diamond), W106A (x), and $\Delta 106$ mutants (open circle). 

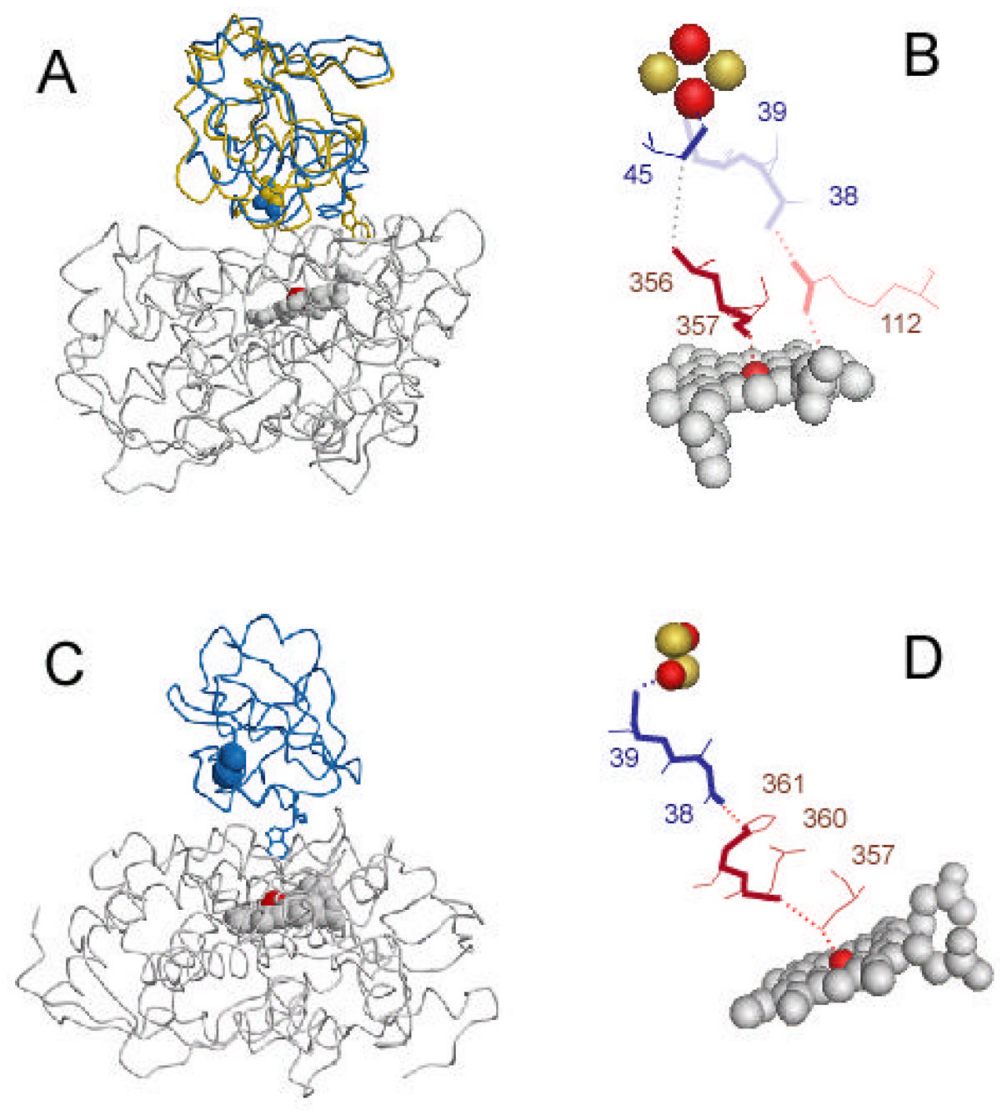

Figure 5.

Models of the P450cam-Pdx ET complexes. A, Superposition of the original (1PUT $\mathrm{Pdx}^{\mathrm{O}}$ in gold (15)) and optimized Pochapsky' models (Model 1, molecule B of 1XLQ Pdx ${ }^{\mathrm{r}}$ in blue). $B$, Two Pdx ${ }^{\mathrm{r}}$-to-P450cam ET pathways (highlighted in bold lines) predicted for Model 1 by HARLEM (45) depending on whether single iron atoms or the entire cofactor groups were chosen as an electron donor/acceptor. The Fe-to-Fe route, shown in dark blue and brick colors, follows from the iron-sulfur cluster to the Cys45 ligand and via space jump to the Leu356Cys357 peptide of $\mathrm{P} 450 \mathrm{cam}$. The [2Fe-2S]-to-heme path, shown in light blue and pink colors, proceeds from the $[2 \mathrm{Fe}-2 \mathrm{~S}]$ ligand Cys39 through the main and side chain atoms of Asp38 and via the Asp38-Arg112 $\mathrm{P} 450$ and Arg112 $\mathrm{P} 450$-propionate hydrogen bonds to the heme group. $C$, An optimized oxy-P450cam-Pdx ${ }^{\mathrm{r}}$ complex generated by GRAMM (Model 2, Pdx shown in blue). $D$, The unique ET root predicted for Model 2 by HARLEM follows from the [2Fe-2S] cluster through the Cys39 ${ }_{\mathrm{Pdx}}-\mathrm{Asp} 38_{\mathrm{Pdx}}$ and His361 ${ }_{\mathrm{P} 450}-\mathrm{Gln} 360_{\mathrm{P} 450}$ peptides and the

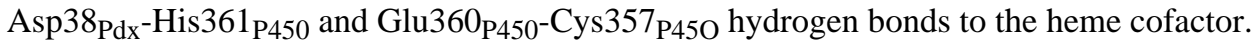




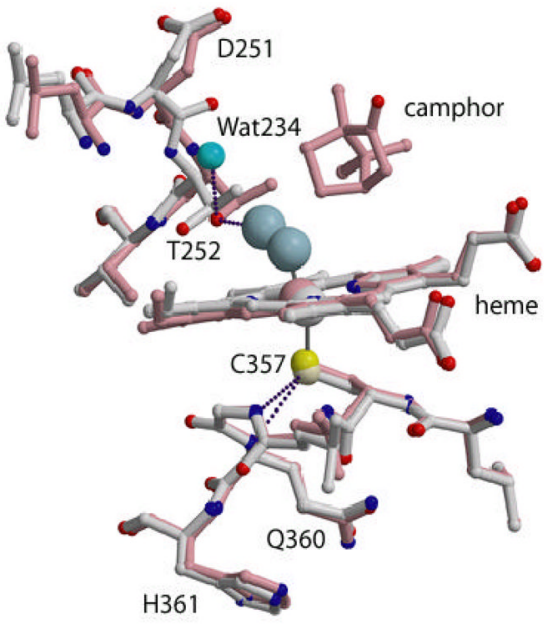

A
B
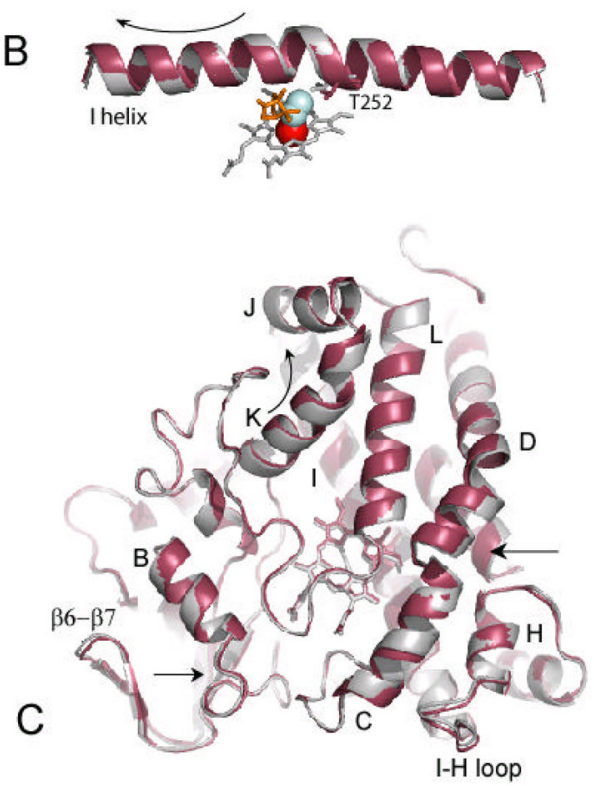

Figure 6.

Structural changes in the active site $(A)$, I helix $(B)$, and the proximal face $(C)$ of P450cam induced by one-electron reduction and dioxygen binding. Superposition of the crystal structures of ferric (gray (42)) and oxy-P450cam (pink, maroon (35)) was performed using the program LSQMAN (78). The $\mathrm{O}_{2}$ and catalytically important water molecules are shown in blue. Rearrangements in the oxygen-binding groove and the I helix transmit via adjacent and neighboring helices $\mathrm{E}$ and $\mathrm{J}$ and an $\mathrm{H}-\mathrm{I}$ loop to helices $\mathrm{C}, \mathrm{D}, \mathrm{H}$, and $\mathrm{K}$ that constrict around the hydrophobic pocket and make it more pronounced. Arrows show redox-linked movements of structural elements. 


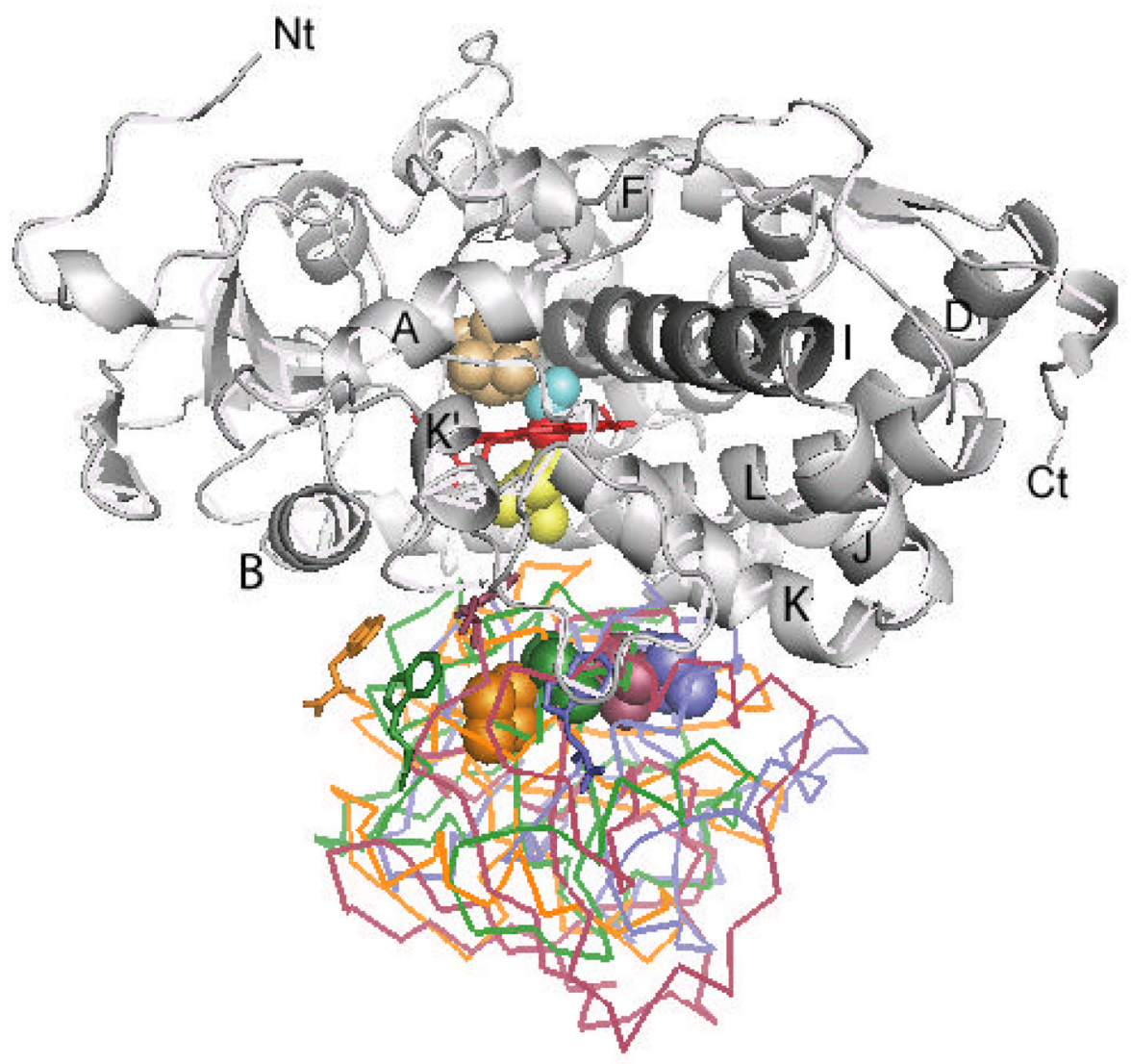

Figure 7.

Four plausible orientations between oxy-P450cam (gray) and $\mathrm{Pdx} \mathrm{r}^{\mathrm{r}}$ corresponding to solutions 4, 28, 46, and 49 generated by GRAMM (blue, green, orange, and maroon, respectively) where the Fe-Fe distance is less than $20 \AA$. The helix designation in P450cam is according to Poulos et. al (79) with the functionally important I helix highlighted in dark gray. The heme iron (red), camphor (beige), dioxygen (cyan), and the iron-ligating Cys357 (yellow) in P450cam and the $[2 \mathrm{Fe}, 2 \mathrm{~S}]$ cofactors in $\mathrm{Pdx}$ are in cpk representation. 


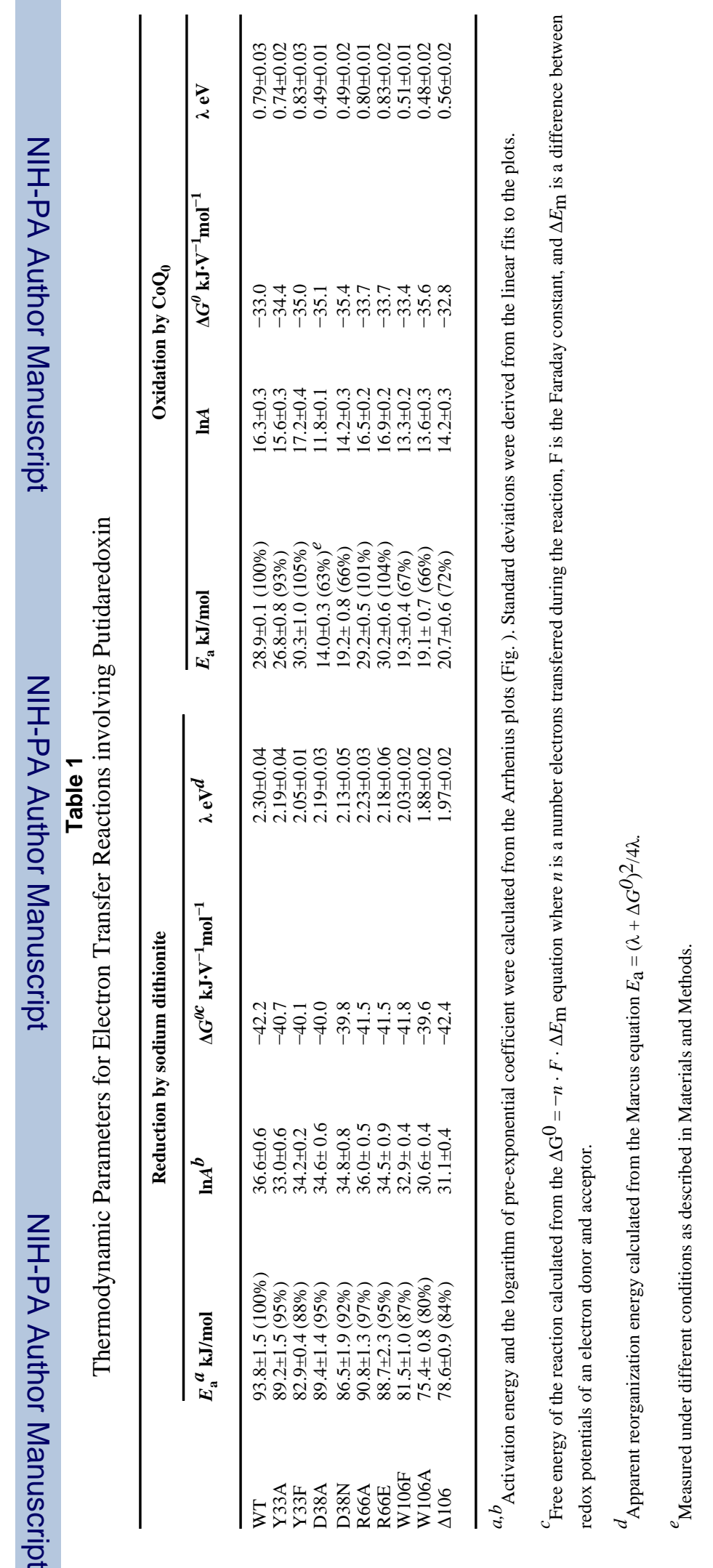




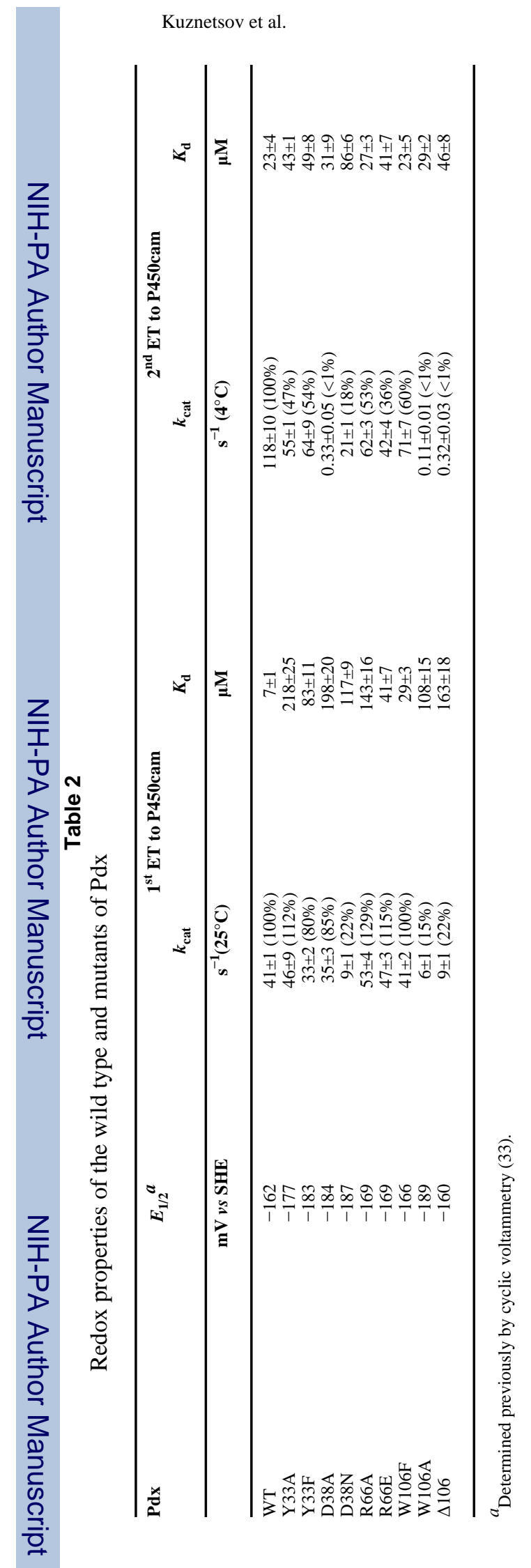

Page 24 


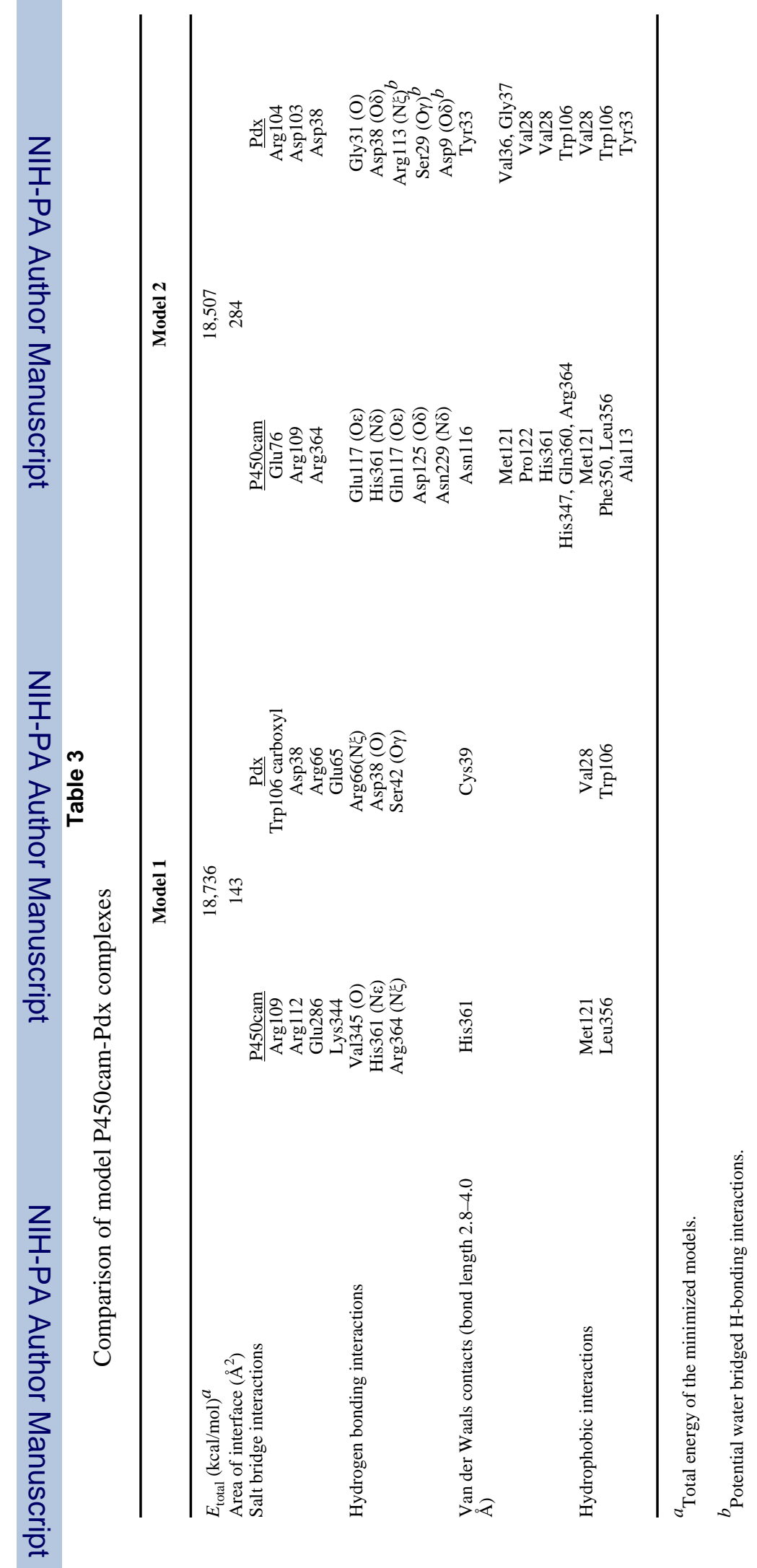




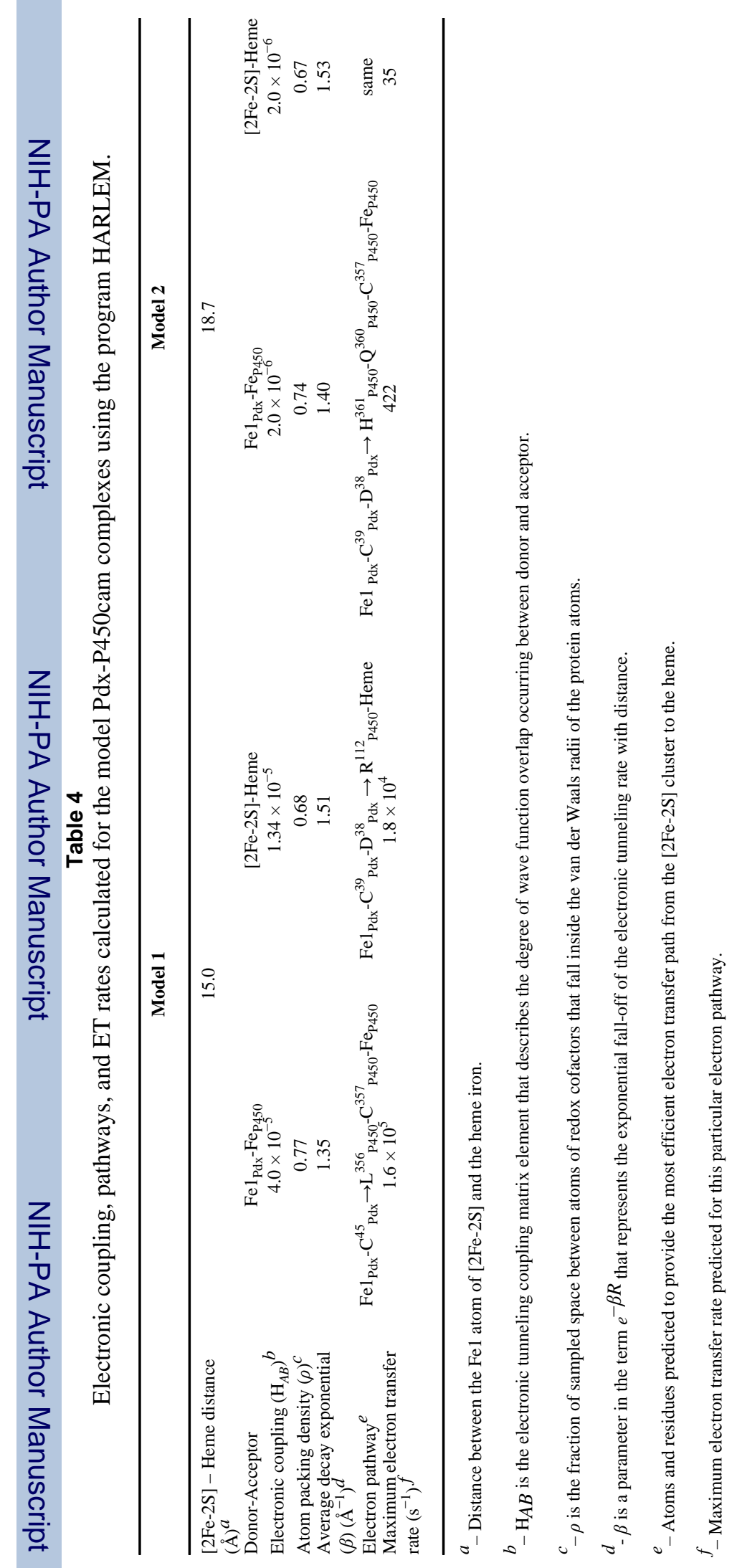

